\section{Eugen Bleuler (1857-1939), an early pioneer of evidence based medicine}

The famous Swiss psychiatrist, Eugen Bleuler (figure 1), is well known for his seminal work on psychosis, for having coined the term 'schizophrenia' and for his disputes about psychoanalysis with Sigmund Freud. Less known is the fact that Bleuler was a harsh critic of many of the methods and practices of his colleagues. In a small book, first issued in 1919, when he was 61 years old, he castigated many of his contemporaries for sloppy thinking and poor methods, both in medical practice and research. ${ }^{1}$

The title of the book sounds too good in German not to quote it fully: Das Autistisch-Undisziplinierte Denken in der Medizin und seine Überwindung. This provocative title can be translated as Autistic and undisciplined thinking in medicine, and how to overcome it. In the first chapter, Bleuler asserts that many of the cognitive habits of doctors can be compared with what he observed in his patients: a magical way of thinking, more aimed at the fulfilment of wishes and hopes than reflecting and analysing reality: hence 'autistic thinking'. ${ }^{2}$ According to Bleuler, this pathological cognitive style is paramount in medicine, far more than in other sciences. ${ }^{3} \mathrm{He}$ explains this by the complexity and obscurity of most medical knowledge, in combination with the need to defy sickness and death. The combination of our limited knowledge and the need to act causes what he calls 'Primitivreaktionen'. 4 These are a form of cognitive reflexes, based on tradition and habits, which create the illusion in both doctors and their patients that something useful is done.

Bleuler was of the opinion that autistic thinking pervades all areas of medicine, but especially prevention and treatment. He gives numerous examples of popular treatments in his time that were ineffective or even dangerous, such as electrotherapy, hydrotherapy and many dietary remedies. ${ }^{5}$ One only has to visit one of the historic European spas to get an impression of the popularity of water treatments around the fin de siècle and later. Bleuler observed that the efficacy of these treatments is unproven and probably non-existent. It would often be better to do nothing at all, instead of prescribing worthless remedies. Moreover, many ailments recover spontaneously. Even a seemingly harmless treatment, which many might now accept for its placebo effect, can have adverse effects, according to Bleuler: it may reinforce the conviction of the patient that he is really ill and even impede recovery. ${ }^{6}$ To give his policy of doing nothing the same dignity as the popular remedies with their ostentatious names, he-jokingly—proposes the term 'udenotherapy', which literally means 'non-treatment' (from the Greek 'ouden', nothing). ${ }^{7}$

In the realm of pharmacological treatments the situation was not much better. Bleuler had little confidence in the methods used to develop drugs, which he summarised as follows: when a new substance is believed to have therapeutic properties, it is tested on a couple of animals or humans, and "in the great majority of these experiments nobody is killed". ${ }^{8}$ Usually the drug is targeted at a condition with a benign natural course, or one that is easily influenced by suggestion. The doctor who discovered the drug believes in its beneficial effects, which strongly biases his observations. The outcomes of therapeutic

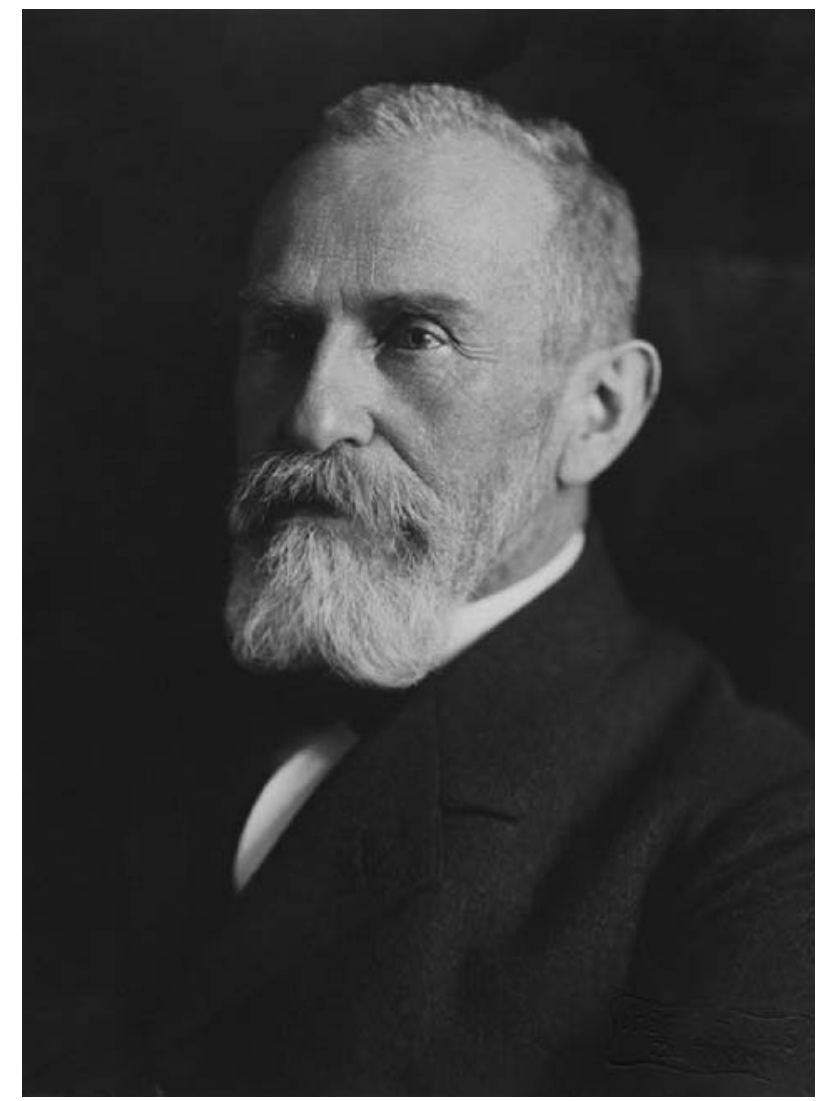

Figure 1 Eugen Bleuler (1857-1939).

experiments are usually caused by a play of chance, and only the favourable results are published, not the negative ones. Controlled experiments are rarely done and, if they are, the results are unreliable because the control patients differ from the treated ones. ${ }^{10}$ The next step is to print a glamorous brochure and offer free samples of the drug, so doctors can see for themselves how well it works in practice.

After his analysis of the dismal state of affairs in medical research and practice, Bleuler proposes a number of measures to improve the quality of medical research, which he called Forderungen für die Zukunft (requirements for the future). ${ }^{11}$ Some of these ideas had already been developed long before, by the French pioneers Louis and Gavarret, but he was not aware of their publications. For Gavarret, this was not unusual since even the renowned British statistician Greenwood (1880-1949) did not know the work of Gavarret. Bleulers' proposals show some of his surprisingly modern insights. First he demanded that, in order to examine the efficacy of any treatment, it is essential to compare the results in two groups of patients who are as similar as possible in all aspects except the treatment. To achieve this he proposed alternating assignment of patients to treatment $\mathrm{A}$ or treatment $\mathrm{B}$ (or nothing). ${ }^{12} \mathrm{He}$ did not come across the idea of randomisation, which had to wait for Ronald A Fisher, who described it in 1935 in his legendary book The design of experiments. ${ }^{13}$ Bleuler stresses the need to examine sufficiently large groups to avoid chance results. Also, he recommended that "for almost all conclusions the degree of their probability should be determined, if possible expressed in numbers". ${ }^{14}$ He regarded so called negative results as at least as important as positive findings: "for science, there are no negative results". ${ }^{15}$ They should be published in a registry, so that 
everyone can have access to all data. This should also help to counteract the tendency to try and find positive results at all cost, which he regarded as "a practice that results in much pointless labour and many false results". ${ }^{16}$ This issue has later been elaborated by John Ioannidis in his influential paper 'Why most published research findings are false' (2005). ${ }^{17}$

Bleuler aimed his criticism not only at the poor state of medical research and practice, he also had recommendations for journal editors and medical teachers. Medical publications should be concise, with a summary and a numbered list of references. ${ }^{16}$ Now commonplace, but in 1919 revolutionary, and much needed. As to medical education, he advised that medical students should receive at least some instruction in medical psychology and ethics. ${ }^{18}$ He strongly condemned the practice of medical professors lecturing their students ad nauseam without getting any kind of feedback ("a completely perfidious, autistic institution"). ${ }^{19}$ This was truly revolutionary in the authoritarian teaching culture at that time.

This brief summary of Bleulers' insights shows that he was far ahead of many of his contemporaries. His proposals to improve medical research and practice laid out a programme that was only realised slowly during the decades after the Second World War. Many pioneers after him, such as Alvan Feinstein, David Sackett and Archie Cochrane, came to similar conclusions, and formulated the programme which we now call 'evidence based medicine', a term coined by Gordon Gyatt somewhere in 1990. Re-reading of Bleulers' remarkable book shows his farsighted analysis of the many shortcomings of medical science and practice in 1919, and the effective remedies he proposed. His name should be enlisted in the hall of fame as one of the true pioneers of evidence based medicine.

\section{Jan Stam, Marinus Vermeulen}

Department of Neurology, Academic Medical Centre, University of Amsterdam, Amsterdam, The Netherlands

Correspondence to Professor I Stam, Department of Neurology, Academic Medical Centre, University of Amsterdam, Meibergdreef 9, Amsterdam 1105 AZ,

The Netherlands; j.stam@amc.uva.nl

\section{Competing interests None.}

Provenance and peer review Not commissioned; externally peer reviewed.

To cite Stam J, Vermeulen M. J Neurol Neurosurg Psychiatry 2013;84:594-595.
Accepted 14 November 2012

Published Online First 12 December 2012

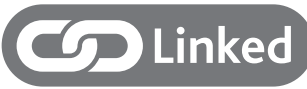

http://dx.doi.org/10.1136/jnnp-2012-304330

J Neurol Neurosurg Psychiatry 2013;84:594-595. doi:10.1136/jnnp-2012-303715

\section{REFERENCES}

1 Bleuler E. Das Autistisch-Undisziplinierte Denken in der Medizin und Seine Überwindung. 3e Auflage. Berlin: Springer, 1922.

2 Bleuler E. Das Autistisch-Undisziplinierte Denken in der Medizin und Seine Überwindung. $3^{e}$ Auflage. Berlin: Springer, 1922:1.

3 Bleuler E. Das Autistisch-Undisziplinierte Denken in der Medizin und Seine Überwindung. 3e Auflage. Berlin: Springer, 1922:2.

4 Bleuler E. Das Autistisch-Undisziplinierte Denken in der Medizin und Seine Überwindung. $3^{e}$ Auflage. Berlin: Springer, 1922:185.

5 Bleuler E. Das Autistisch-Undisziplinierte Denken in der Medizin und Seine Überwindung .3e Auflage. Berlin: Springer, 1922, 18:20-1.

6 Bleuler E. Das Autistisch-Undisziplinierte Denken in der Medizin und Seine Überwindung. $3^{e}$ Auflage. Berlin: Springer, 1922:14.

7 Bleuler E. Das Autistisch-Undisziplinierte Denken in der Medizin und Seine Überwindung. $3^{e}$ Auflage. Berlin: Springer, 1922, 15:162.

8 Bleuler E. Das Autistisch-Undisziplinierte Denken in der Medizin und Seine Überwindung. $3^{e}$ Auflage. Berlin: Springer, 1922:40.

9 Bleuler E. Das Autistisch-Undisziplinierte Denken in der Medizin und Seine Überwindung. $3^{e}$ Auflage. Berlin: Springer, 1922:41.

10 Bleuler E. Das Autistisch-Undisziplinierte Denken in der Medizin und Seine Überwindung. $3^{e}$ Auflage. Berlin: Springer, 1922:107.

11 Bleuler E. Das Autistisch-Undisziplinierte Denken in der Medizin und Seine Überwindung. 3e Auflage. Berlin: Springer, 1922:104.

12 Bleuler E. Das Autistisch-Undisziplinierte Denken in der Medizin und Seine Überwindung. $3^{e}$ Auflage. Berlin: Springer, 1922:108.

13 Fisher RA. The design of experiments, 8th Edn. Edinburgh: Oliver and Boyd, 1966 (1935).

14 Bleuler E. Das Autistisch-Undisziplinierte Denken in der Medizin und Seine Überwindung. $3^{e}$ Auflage. Berlin: Springer, 1922:112.

15 Bleuler E. Das Autistisch-Undisziplinierte Denken in der Medizin und Seine Überwindung. 3e Auflage. Berlin: Springer, 1922:180.

16 Bleuler E. Das Autistisch-Undisziplinierte Denken in der Medizin und Seine Überwindung, 3e Auflage. Berlin: Springer, 1922:181.

17 loannidis JP. Why most published research findings are false. PLoS Med 2005;2: e124.

18 Bleuler E. Das Autistisch-Undisziplinierte Denken in der Medizin und Seine Überwindung. $3^{e}$ Auflage. Berlin: Springer, 1922:173-5.

19 Bleuler E. Das Autistisch-Undisziplinierte Denken in der Medizin und Seine Überwindung. $3^{e}$ Auflage. Berlin: Springer, 1922:177. 